1 This manuscript is a preprint and has been submitted for publication at Fronteirs in Environmental Science. 2 Subsequent versions may have slightly different content. The DOI of the peer reviewed publication will be 3 provided if accepted. Please contact the authors if you have any questions or comments on this manuscript. 



\title{
Accuracy vs Realism: Does including reservoirs improve hydrological models?
}

\author{
Simone van Langen ${ }^{1, *}$, Chanokun Wannasin ${ }^{1}$, Tim van Emmerik ${ }^{1}$, Germano \\ G. Ribeiro Neto ${ }^{1}$ and Lieke Melsen ${ }^{1, *}$ \\ ${ }^{1}$ Hydrology and Quantative Water Management Group, Wageningen University and \\ Research, Wageningen, The Netherlands \\ Correspondence*: \\ Simone van Langen, Lieke Melsen \\ simone.vanlangen@outlook.com, lieke.melsen@wur.nl
}

\section{ABSTRACT}

Brazil has invested considerably in the reservoir construction during the past decades, mainly for irrigation and hydro-power generation. Despite their large impact on catchment hydrology, reservoir dynamics are often not included in hydrological models due to their complexity. In this study, we investigated the effect of including reservoir dynamics (realism) in hydrological models on the model performance (accuracy). Combined, realism and accuracy form the model fidelity. We used the HBV-EC and GR4J models to simulate hydrological processes and daily streamflow of 403 catchments across Brazil in two scenarios, with and without reservoirs. The model performances were assessed with the Kling Gupta Efficiency (KGE) and its components, and were compared between the models and scenarios. We found a significant increase in the HBV-EC model performance when the reservoirs were taken into account, although the overall performance was relatively poor. The average KGE increased from 0.21 without the reservoirs to 0.40 with the reservoirs. The GR4J model, on the other hand, showed better overall performance, but without the improvement when including the reservoirs; the average KGE slightly decreased from 0.57 to 0.56 . In the catchments with the largest reservoir capacity, HBV-EC in the scenario with reservoirs outperformed GR4J in both scenarios. We note that better model performance can still be obtained with a smaller spatial scale or other methods of including reservoirs, which require more data and detailed studies. With this paper, we demonstrate that model performance can improve when including reservoir dynamics, but this depends on model structure and does not always increase model fidelity.

Keywords: reservoirs, socio-hydrology, Brazil, model fidelity, human impact, HBV, GR4J

\section{INTRODUCTION}

Models are simplifications of reality and therefore inherently come with uncertainties. Model fidelity is the degree to which the model simulations relate to the real world. Fidelity is achieved both by the sufficient accuracy (the simulations match the observations) and by the realism of the model (the relevant processes are well represented):

$$
\text { fidelity }=\text { accuracy }+ \text { realism. }
$$

To get the right answers for the right reasons (Kirchner, 2006, p.1), not only a good model performance (accuracy), but also a realistic representation (where deciding upon what is realistic is part of the art of modeling) are required. 


\section{METHODS}

\subsection{Study area and data} accuracy (DelSole and Shukla, 2010). modeling exercise across Brazil. characteristics.

The most important natural processes are generally included in most process-based hydrological models, and continuous efforts are being made to increase their realism (Clark et al., 2011). This works well for modeling pristine catchments, but can be insufficient for coupled human-water systems (Van Emmerik et al., 2014). Most natural catchments have been anthropogenically altered, for example by abstracting water from groundwater sources, constructing reservoirs and dams, and developing irrigation systems (De Graaf et al., 2019). Human interference in catchments can cause significant changes in streamflow (Van Loon et al. 2019; Wada et al., 2017; Wanders and Wada, 2015; Woo et al., 2008). To better describe the two-way feedbacks in coupled humen-water systems, new concepts like socio-hydrology (Sivapalan et al., 2012) and water science in the Anthropocene (Savenije et al., 2014; Van Loon et al., 2016) have been introduced. Furthermore, there is an increasing interest in incorporating human interference into hydrological models to increase model fidelity. This is not trivial, since there are many challenges, including fundamental questions on how to incorporate complex human influences in classical hydrological modeling approaches, and data availability issues regarding water management and decision making (Wada et al., 2017; Zhou et al., 2016). Because of these challenges, improved model realism does not always lead to improved model

In this study, we focus on including human influence, by means of reservoirs, in hydrological modeling across catchments in Brazil. Brazil has a dense network of reservoirs (Cavalcante et al., 2020; Souza Filho, 2009) with a high socio-economic relevance; almost $70 \%$ of the country's electricity production comes from hydropower plants (Mello et al., 2021). Furthermore, the Brazilian reservoirs are used to ensure the water supply of agricultural production (Multsch et al., 2020) and flood control (Fleischmann et al., 2019), in addition to being the main source of water for human consumption in the semiarid region (Braga et al. 2012; Mamede et al., 2018). In turn, these reservoirs have significant impacts on downstream hydrology (e.g., Almeida et al., 2020; Cavalcante et al., 2020; Dantas et al., 2020; Fantin-Cruz et al., 2015; Souza Filho, 2009) and ecology: they can lead to flooding of natural habitats, interfere with the migratory cycle of fish and alter the transport of sediments and nutrients (Best, 2019; Latrubesse et al., 2017). The recently released Catchment Attributes and MEteorology for Large-sample Studies - Brazil (CAMELS-BR) data set, introduced by Chagas et al. (2020), contains both data on total reservoir capacity and hydrometeorological time series in Brazilian catchments. These data offer new opportunities to investigate how including reservoir dynamics in the hydrological model representation affects the model performance in a large-scale

The aim of this study is to investigate the effect of including reservoirs in hydrological models (increasing realism) on model performance (accuracy) across catchments in Brazil, to see if model fidelity can be improved. To achieve this goal, 403 Brazilian catchments were modelled with two commonly used hydrological models. The model performance was compared between two scenarios, one with and one without reservoirs. This comparison made it possible to study the effect of including reservoirs on model performance for different model structures across a variety of catchments with different climates and

Brazil is of particular interest to investigate reservoirs and their impacts on hydrological modeling. Due to the large number of reservoirs across the country (thousands, although the exact number is unknown, Mulligan et al., 2020), they are likely to intervene the hydrological system at a large scale. The large size of Brazil allows this study to consider a great variety in catchment characteristics, such as catchment size, 
climatology, topography and land use. Therefore, studying reservoir effects on hydrological modeling in Brazil can benefit the understanding and improvement of hydrological modeling not only for Brazilian catchments, but also for catchments in neighboring countries and regions.

Our study includes 403 (partly nested) catchments across Brazil, as shown in Figure 1. These are the catchments in the CAMELS-BR data set that have a reservoir capacity greater than zero (Chagas et al. 2020). Some cross-boundary catchments that only lay partly in Brazil are also included in this data set. Brazil has a great variation in climate and land cover. The Northern region is mostly covered by the Amazon forest (59\% of the Brazilian territory), with an average annual temperature of $30^{\circ} \mathrm{C}$ and an annual accumulated precipitation that can exceed $3000 \mathrm{~mm}$. This contrasts the savanna region in the Northeast (Brazilian Caatinga) and Midwest (Brazilian Cerrado), with average annual precipitation sums between 400-800 mm and 800-1000 mm, respectively. In the Southeast, Midwest and South, large plantations can be found, which share space with other natural biomes, such as the Atlantic Rainforest and Araucaria Pine Forest. Annual precipitation in this region varies between 1000-2000, with an average annual temperature around $20^{\circ} \mathrm{C}$.

All the data used in this study were obtained from the CAMELS-BR data set, including catchment characteristics (e.g., soil, land use and topography) and hydrometeorological data for model forcing and calibration. For most catchments, the daily time series of observed streamflow and reanalysed meteorological forcing data are available from the year 1980 to 2018. However, the time series are shorter for some catchments. Therefore, we only employed data from 1990 to 2008, which made it possible to include all catchments with reservoirs for an equally long period. This 19-years period still allows for proper calibration and validation of the models.
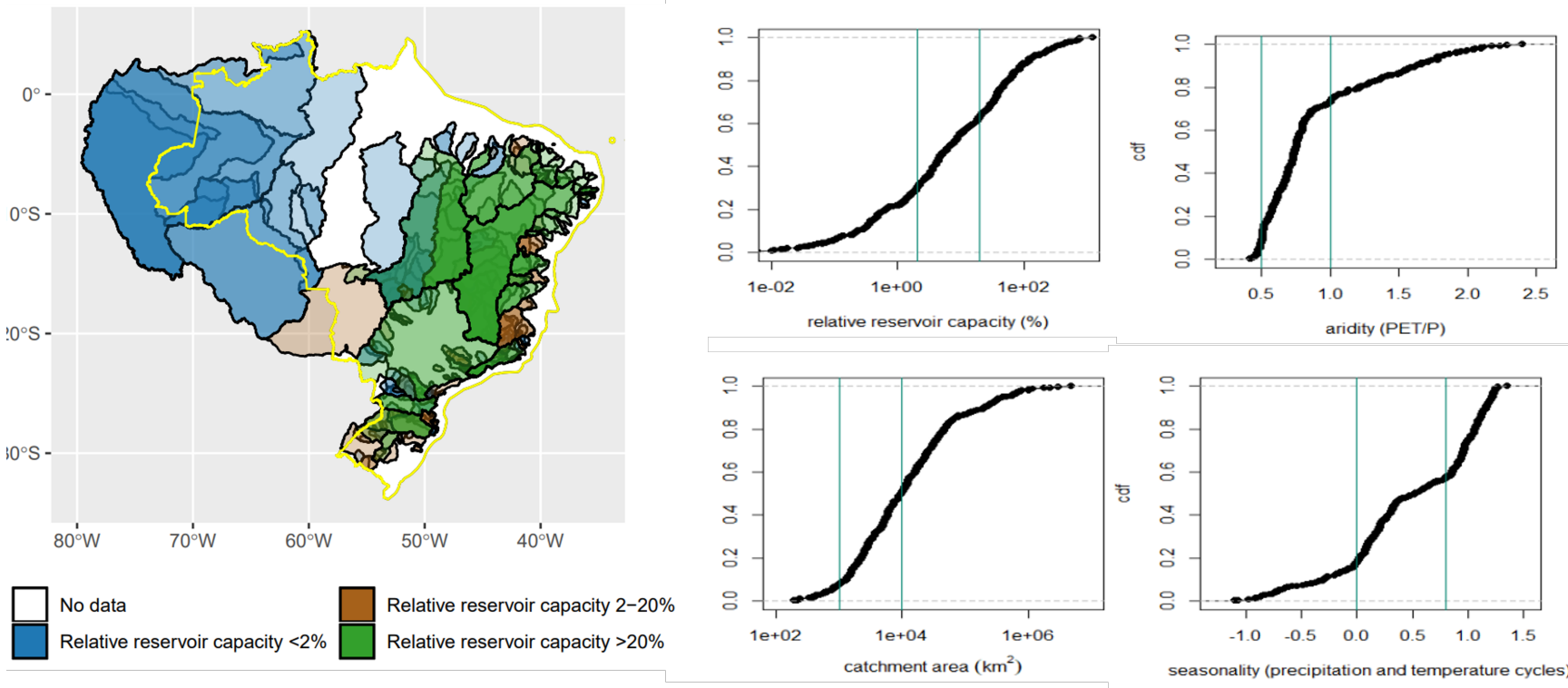

Figure 1. Selected study catchments in Brazil. Different colors in the left panel indicate the reservoir capacity as the percentage of the total annual streamflow for each catchment. The boundary of Brazil is shown in yellow. The reservoirs were assumed to be located at the outlet of each catchment. The cumulative distribution curves of the catchment area (upper middle panel), relative reservoir capacity (lower middle panel), aridity (upper right panel) and seasonality (lower right panel) are shown. The vertical lines indicate the limits of the defined catchment classes for the ANOVA analysis (see Table 5). The three classes, divided by the vertical lines, in the left upper cdf panel coincide with the classes indicated in the map on the left. 
The required meteorological forcing data in this study were precipitation, potential evaporation, which also includes transpiration, and minimum and maximum temperature. The CAMELS-BR data set contains different types of data for precipitation, including Climate Prediction Center (CPC), Multi-Source WeightedEnsemble Precipitation (MSWEP) and Climate Hazards Group InfraRed Precipitation with Station data (CHIRPS). These data sets are all similar, but with different collection methods as well as spatial and temporal scales. We decided to use the CHIRPS precipitation data set, since it has the highest spatial resolution $\left(0.05^{\circ}\right)$ (Chagas et al., 2020). This product has shown good performance in several Brazilian regions (e.g., Paca et al., 2020; Paredes-Trejo et al., 2017), although it was also shown that CHIRPS has the tendency to underestimate extreme precipitation events across Brazil (Cavalcante et al., 2020).

For reservoir-related data, CAMELS-BR only provides the total reservoir capacity, which is a fixed value for each catchment. As such, this study also aimed to assess whether this information is sufficient for including the reservoirs in hydrological models, or whether more detailed information should be gathered for that purpose. Next to the total reservoir capacity, the CAMELS-BR contain data on consumptive water use, which may be included in the modeling structures as an extra outflow of water. However, this outflow is small $(<10 \%$ of the total streamflow for the majority of the catchments, and for 173 out of 403 catchments even $<1 \%$ ) compared to other outflows. Its influence on the model performance was assumed negligible and therefore it was not included in this study.

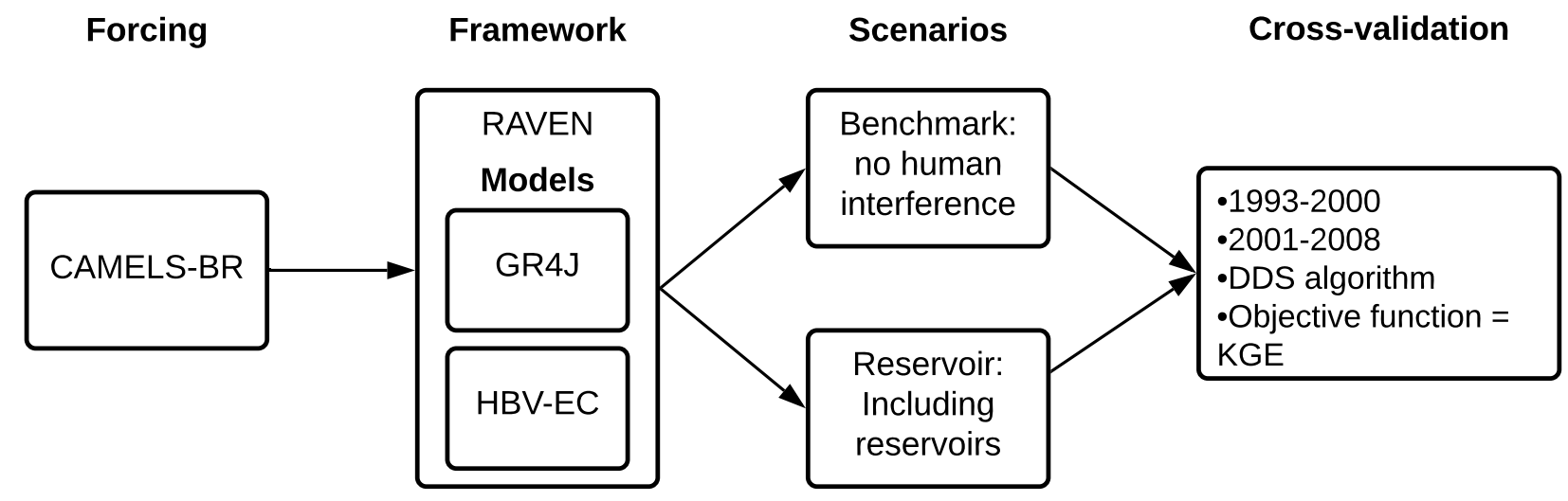

Figure 2. Overview of the model approach.

\subsection{Hydrological modeling}

Two hydrological modeling structures were compared, using the RAVEN modular modeling framework (Craig et al., 2020). RAVEN is a flexible framework, which allows many different algorithms to be used for different parts of the water cycle as well as various routing mechanisms. Several hydrological modeling structures can be reproduced nearly exact: UBCWM (Quick, 1995), HBV-EC (Bergström, 1995), HMETS (Martel et al., 2017), MOHYSE (Fortin and Turcotte, 2006) and GR4J (Perrin et al., 2003). This framework was chosen because it includes some modules that allow modeling of human interference. It can thus easily be adapted to include the reservoir dynamics.

\subsubsection{HBV-EC and GR4J models and scenarios}

The HBV-EC and GR4J models were selected in this study. HBV-EC is a Canadian version of the HBV (in Swendish, Hydrologiska Byråns Vattenbalansavdelning) model (Bergström, 1995; Lindström et al. 1997). It is a semi-distributed conceptual model with 16 parameters, employed in this study as a lumped 
Table 1. Overview of the HBV-EC and GR4J models with the RAVEN interpretation

\begin{tabular}{|c|c|c|}
\hline & GR4J & HBV-EC \\
\hline $\begin{array}{l}\text { Water } \\
\text { inflow }\end{array}$ & rain + snow & rain + snow \\
\hline $\begin{array}{l}\text { Surface } \\
\text { water }\end{array}$ & $\begin{array}{l}\text { - Ponded water } \\
\text { - Water flowing to } \\
\text { catchment outlet } \\
\text { - Reservoir }\end{array}$ & $\begin{array}{l}\text { - Ponded water } \\
\text { - Water flowing to } \\
\text { catchment outlet } \\
\text { - Reservoir }\end{array}$ \\
\hline Soil & $\begin{array}{l}4 \text { conceptual layers } \\
\text { - Product store (top soil) } \\
\text { - Temporary store } \\
\text { - Routing store } \\
\text { - Groundwater }\end{array}$ & $\begin{array}{l}\text { - Top soil } \\
\text { - Fast and slow } \\
\text { reservoir from } \\
\text { where base-flow } \\
\text { originates }\end{array}$ \\
\hline Snow & $\begin{array}{l}\text { Simple balance between } \\
\text { snow and ponded water }\end{array}$ & $\begin{array}{l}\text { More complex } \\
\text { snow balance with } \\
\text { liquid snow that } \\
\text { can refreeze } \\
\text { between snow and } \\
\text { ponded water. }\end{array}$ \\
\hline $\begin{array}{l}\text { Routing } \\
\text { to outlet }\end{array}$ & $\begin{array}{l}\text { Fixed } 10 \% \text { fast (through } \\
\text { temporary soil store) } \\
\text { and } 90 \% \text { slow runoff } \\
\text { (through routing store) }\end{array}$ & $\begin{array}{l}\text { Separated fast and } \\
\text { slow runoff based } \\
\text { on parameters }\end{array}$ \\
\hline $\begin{array}{l}\text { Water } \\
\text { outflow }\end{array}$ & $\begin{array}{l}\text { Evaporation from: } \\
\text { - Soil } \\
\text { - Reservoirs } \\
\text { Catchment outlet } \\
\text { Groundwater }\end{array}$ & $\begin{array}{l}\text { Evaporation from: } \\
\text { - Soil } \\
\text { - Canopy } \\
\text { - Reservoirs } \\
\text { Catchment outlet }\end{array}$ \\
\hline $\begin{array}{l}\text { Number of } \\
\text { parameters }\end{array}$ & $\begin{array}{l}16 \\
\text { (17 with reservoir) }\end{array}$ & $\begin{array}{l}6 \\
\text { (7 with reservoir) }\end{array}$ \\
\hline
\end{tabular}

model. GR4J (in French, modèle du Génie Rural à 4 paramètres Journalier) is a four-parameter lumped conceptual rainfall-runoff model developed by Perrin et al. (2003). However, the RAVEN emulation contains two additional parameters to add a snow routine to GR4J. In general, HBV-EC has a slightly more complex structure than GR4J, but both are relatively simple and widely used in previous studies with good performance (e.g., Engeland and Hisdal, 2009, Payan et al., 2008, Unduche et al., 2018). An overview of the RAVEN interpretations of both models is given in Table 11. The complete model schemes of HBV-EC and GR4J are shown in Figures 8 and 9 , respectively.

To run the models in RAVEN, the readily available templates for the HBV-EC and GR4J models were implemented (Craig et al. 2020). Given that we work with lumped models, each catchment was represented by a single Hydrological Response Unit (HRU). The majority of the parameters in both models were calibrated (see Table 3 for HBV-EC and Table 4 for GR4J). For the few remaining parameters, where possible CAMELS-BR data were used, including soil types, groundwater depth and land use types (like forest fraction).

To include the reservoirs in the model structures, an extra open-water HRU was added, which accounts for the storage of the reservoir and the open water evaporation from the reservoir. Note that the lumped nature of the models implies that the total reservoir capacity is placed at the outlet of the catchment and therefore we do not account for concatenating or cascading effects of reservoirs. This is also not possible with the information provided in CAMELS-BR; only the total reservoir capacity per catchment is provided. The 
lake-like reservoirs require information about the weir coefficient ( $C$; default 0.6 ), crest width (calibrated), maximum depth $(h)$ and surface area $(A) . A\left(\mathrm{~km}^{2}\right)$ and $h(\mathrm{~m})$ can be calculated from the reservoir capacity $\left(V\right.$, in $\left.10^{6} \mathrm{~m}^{3}\right)$ by reversing the equations given by Chagas et al. (2020):

$$
V=0.678 \times(A h)^{0.9229}
$$

for reservoirs for which depth $h$ information was available, and

$$
V=30.682 \times A^{0.9578}
$$

for the reservoirs where depth information was not available.

Two scenarios were investigated in this study: without reservoirs (the so-called benchmark scenario) and with reservoirs included in the model structures (the so-called reservoir scenario). Firstly, the benchmark model performance was assessed by calibrating and running the model without reservoirs. Then, reservoirs were included with an extra HRU, and the models were calibrated again before assessing their performance. 2.2.2 Calibration and cross-validation

Calibration was performed on the discharge using the model-independent, multi-algorithm optimization and calibration tool Ostrich (Matott, 2017). After a warm-up period of three years (1990-1992), the models were calibrated for 8 years and validated for 8 years, which is the duration recommended by Yapo et al. (1996). The cross-validation was performed for the periods 1993-2000 and 2001-2008. For the calibration, the Dynamically Dimensioned Search (DDS) algorithm (Tolson and Shoemaker, 2007) was used with the Kling-Gupta efficiency (KGE) (Gupta et al., 2009) as the objective function.

Particle Swarm Optimization (PSO) was also tested as an alternative calibration algorithm, but this algorithm only provided better results for one out of six calibration runs (based on three random catchments selected to test the methods in both modeling scenarios). The run time of PSO was over thirty minutes for three catchments, compared to just a few minutes with DDS. This made us decide to proceed with DDS. The best parameters found through calibration with DDS were used for validation.

For the benchmark scenario, sixteen and six parameters were calibrated for the HBV-EC and GR4J model, respectively (Table 3 and 4). For the reservoir scenario, the calibration was repeated, with an extra calibration parameter that represents the unknown crest width. The range for this parameter was 1-50 m. This extra parameter provides an extra degree of freedom that could lead to higher model performance, rather than including the reservoir representation per se. However, if only the extra degree of freedom adds to the model performance, this should become visible in the validation (Perrin et al., 2001).

Model performance was assessed using the KGE. Its components were also assessed to determine the main cause of the difference in performances. These components include the linear correlation coefficient $(r)$, bias $(\beta)$ and variability $(\alpha)$ and are all optimal at 1 , with $r$ always being lower than (or equal to) 1 , while $\alpha$ and $\beta$ can also be higher. The components all have equal weights for the performance, as shown in the following equation (Gupta et al., 2009):

$$
\mathrm{KGE}=1-\sqrt{(r-1)^{2}+(\alpha-1)^{2}+(\beta-1)^{2}}
$$

\subsubsection{Model performance analysis}

The change in KGE between the scenarios was assessed with a paired samples t-test. This showed whether including reservoirs increased the model performance significantly across all 403 catchments together. We 


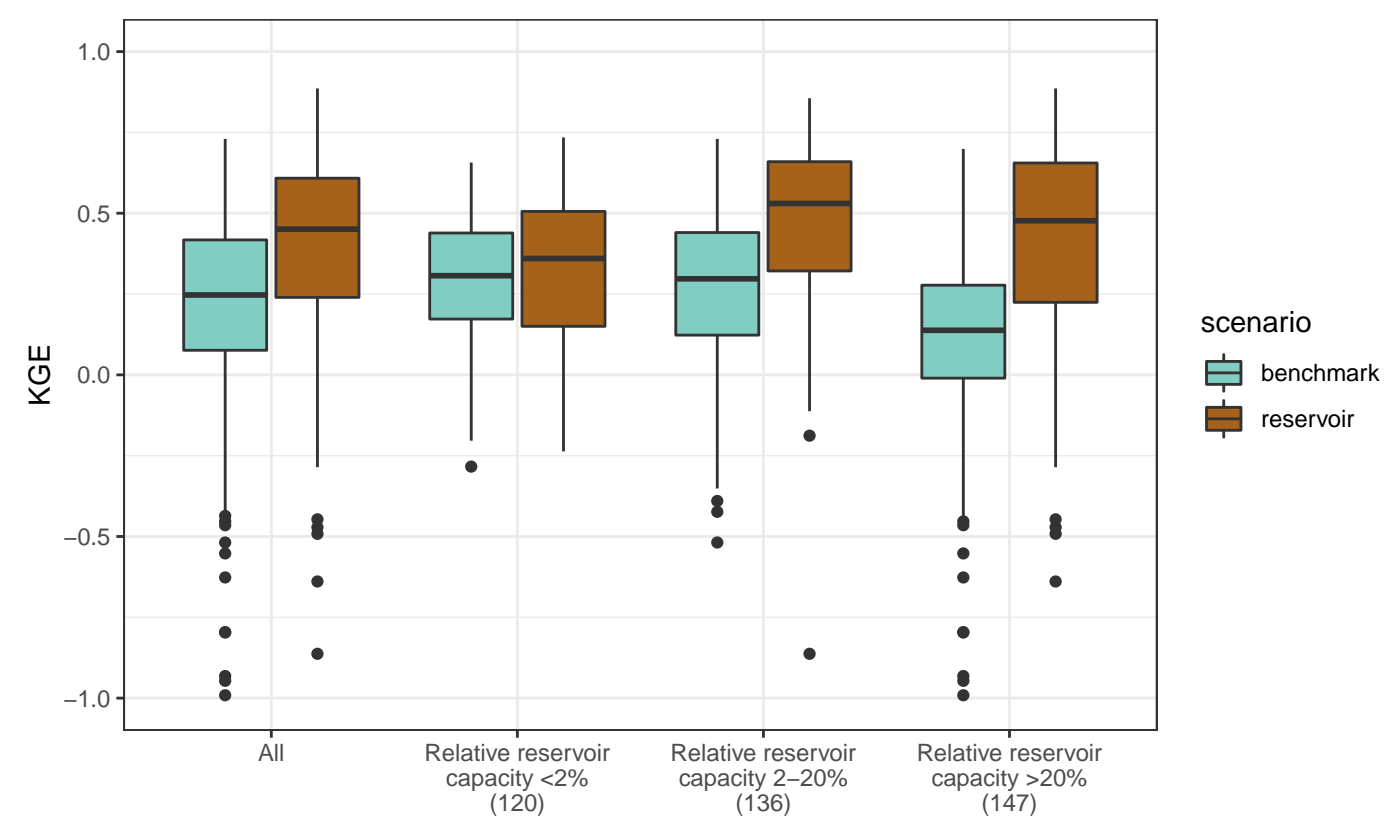

Figure 3. HBV-EC model performance expressed in KGE for all catchments and three classes with different relative reservoir capacity (number of catchments between brackets).

also assessed if catchment characteristics had influence on these results. These catchment characteristics include seasonality, asynchronicity, land use, catchment area, total reservoir capacity, total relative reservoir capacity, latitude and longitude (Table 5). Aridity is here defined as the ratio of mean evaporation to mean precipitation. Seasonality is the timing of the precipitation cycle relative to the temperature cycle, with values close -1 indicating that precipitation is out of phase with temperature, values close to 1 indicating that the cycles are in phase and values close to 0 indicating uniform precipitation throughout the year. Asynchronicity gives the difference in magnitude and phase between the precipitation and evaporation cycles, with the he minimum value of 0 and higher values indicating higher differences between the cycles.

For each catchment characteristic, the 403 catchments were split into three classes, according to the catchment properties in the CAMELS-BR data set. For the division of the classes we opted for an approximately equal number of catchments per class. To assess any significant difference in model performance between the three classes of the same characteristic, an ANOVA test was performed. Next to the effect of using two different scenarios and multiple classes, the effect of model structure was analysed by comparing the performance of the two models.

\section{RESULTS AND DISCUSSION}

\subsection{HBV-EC: model performance improves with including reservoirs}

Figure 3 shows boxplots with the distribution of the KGE for the two simulation scenarios by the HBV-EC model. The reservoir scenario leads to a significantly better performance (mean KGE of 0.40) than the benchmark scenario (mean KGE of 0.21) (Table 6). Despite the achieved improvement in model performance with reservoirs included, a mean KGE of 0.40 is still low and not considered a good overall model performance (Pechlivanidis et al., 2014), i.e., the accuracy is still low.

Visual inspection of hydrographs of ten random catchments revealed that the simulated benchmark streamflow often had higher, narrower peaks and lower base-flows than the observed streamflow. Examples 

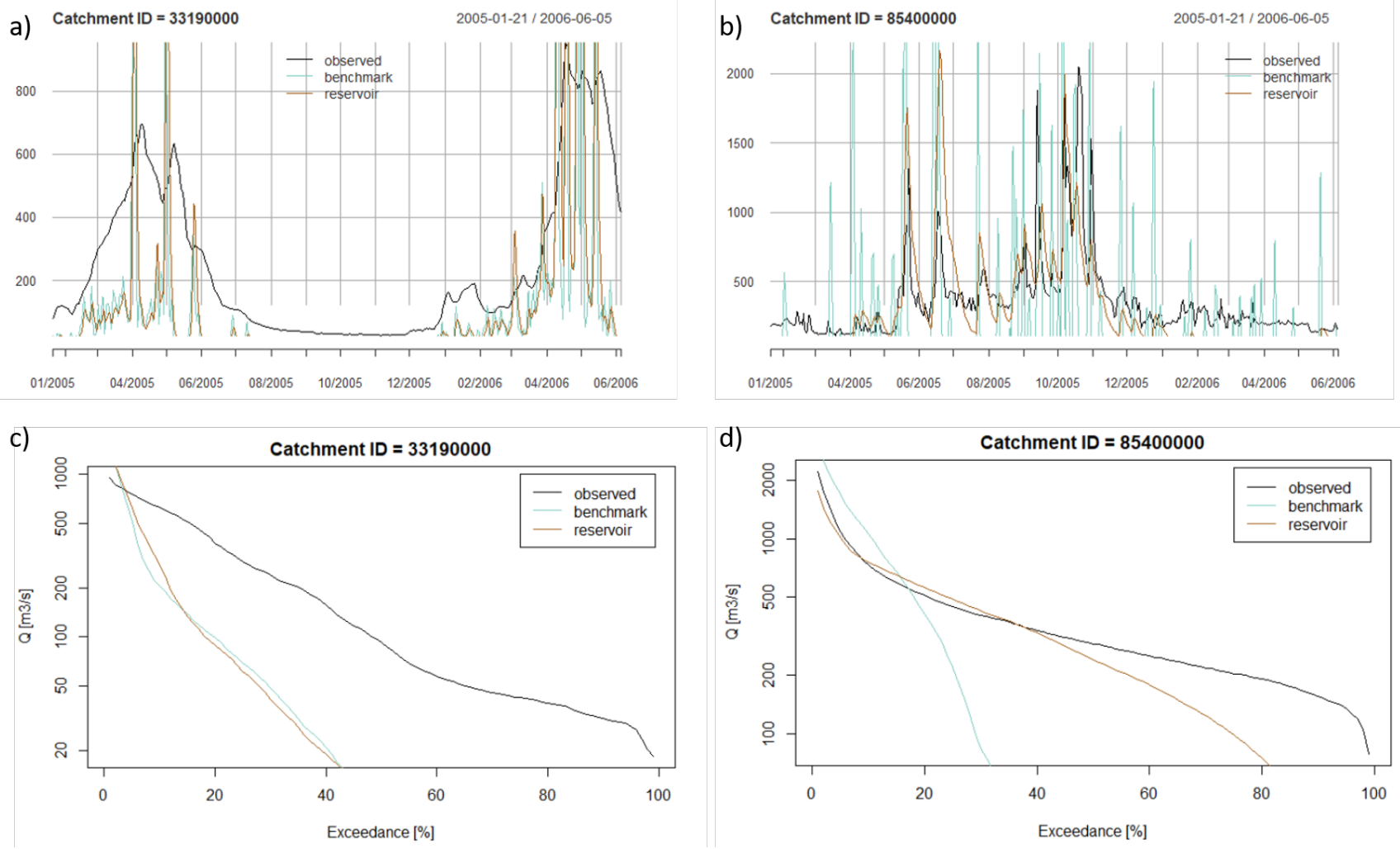

Figure 4. Example hydrographs with streamflow $\left(\mathrm{m}^{3} / \mathrm{s}\right)$ on the y axis $(\mathrm{a}, \mathrm{b})$ and flow duration curves $(\mathrm{c}, \mathrm{d})$ of two catchments with the observed streamflow and the two scenarios simulated using the HBV-EC model. Panels a and c show results for a catchment with relatively poor performance (KGE benchmark $=0.21$, $\mathrm{KGE}$ reservoir $=0.29$ ) and panel $\mathrm{b}$ and $\mathrm{d}$ a catchment with relatively good performance in the reservoir scenario $(\mathrm{KGE}$ benchmark $=-0.05, \mathrm{KGE}$ reservoir $=0.76)$.

of hydrographs and the corresponding flow duration curves of two catchments are provided in Figure 4. showing the more flashy response with more frequently simulated low-flows than observed, and the highest simulated streamflow higher than observed. Including reservoirs in the model attenuates the high peaks and the low-flows in the hydrograph and thereby improves the model performance (Figure $4 \mathrm{~b}$ and d), although for most catchments the performance remains poor (Figure $4 \mathrm{a}$ and c).

When evaluating the separate components of the KGE, the mean of each component improved in the reservoir scenario compared to the benchmark scenario. When the reservoirs were included, the mean $\mathrm{r}$ increased from 0.57 to 0.67 , mean $\alpha$ decreased from 1.22 to 1.01 and mean $\beta$ increased from 0.53 to 0.65 . The values of $\beta$ are below 1 for over $80 \%$ of the catchments for both scenarios, which means that the simulated mean streamflow is generally underestimated.

An advantage of working with a large sample of catchments is that the results can be linked to catchment characteristics. To look into spatial differences, Figure 5 shows the KGE values at the outlet of each catchment. However, no clear spatial pattern was observed. The catchment classes described in Section 2.2.3 and Table 5 were investigated to see whether differences in model performance could be found based on several catchment characteristics. Most classes show the same general trend that the KGE was significantly higher for the reservoir scenario (Table 6). The only class that did not result in a significant improvement was the class with the smallest relative reservoir capacity. This makes sense, since the

7 difference between both scenarios is the addition of the reservoirs, and a smaller reservoir thus leads to 

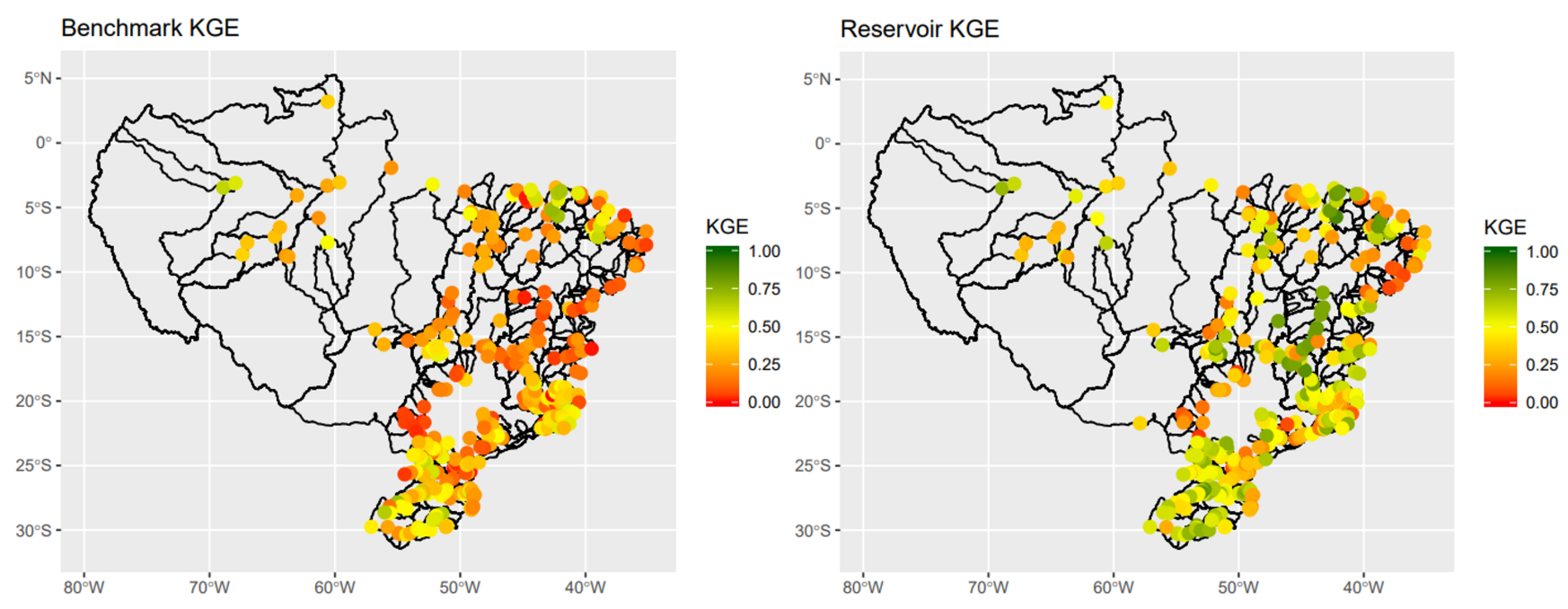

Figure 5. HBV-EC model performance expressed in KGE shown at the outlet of each catchment. The benchmark and reservoir scenarios are shown in the left and right panel, respectively

a smaller difference between both scenarios. This result does show, however, that the improvement in the model performance can be attributed to the conceptual addition of the reservoirs, and not to the extra degree of freedom that the extra reservoir parameter adds.

The largest increase in KGE between the scenarios is seen for the catchments with the largest total reservoir capacity (a mean increase of 0.37 ) and relative reservoir capacity (a mean increase of 0.33 ) (see Table 2). This is depicted in Figure 3. The benchmark scenario performance decreases with relatively larger reservoir capacities, while the reservoir scenario performance increases. However, for both total and relative reservoir capacity, the middle classes have a higher mean KGE for both scenarios compared to the class with the largest (relative) reservoir capacity (see Table 2). There are two potential explanations. Firstly, the more arid the region is, the more water needs to be stored to maintain water supply. HBV-EC has difficulties simulating arid conditions (see the relative poor performance in arid regions, Table 2), while these are also the catchments that profit most from including reservoirs in the model structure. Besides, the semi-arid regions of Brazil are characterized by a high number of small, informal reservoirs (Malveira et al., 2012; Mamede et al., 2012, 2018) which are not represented in the total reservoir capacity and thus challenges hydrological modeling of this region. A second explanation is that many hydropower reservoirs are quite large. Reservoirs for hydropower generation are preferably always close to their maximum capacity and practically "overflow" the entire affluent flow. Their functioning therefore mimics lake behaviour, which is how reservoirs were represented in this study. This shows that the goal of the reservoir might have implications on the hydrological modeling and on how the reservoir should be represented.

The overall model performance achieved with HBV-EC is low but increases with including the reservoirs. Because this effect is the strongest (weakest) in the catchments with relatively large (small) reservoir capacity, this increase can be attributed to the conceptual inclusion of reservoirs in the model structure, thereby increasing model realism. This shows that fidelity increases when reservoir information is included in the HBV-EC model structure, even when the only information available about the reservoirs is the maximum storage capacity. However, the overall model fidelity remains low because of the low accuracy. This low accuracy might be attributed to the model structure (some processes might require more detailed representation, see Fleischmann et al., 2019) and/or the quality of the forcing data. 
Table 2. Summary of the mean model performance (expressed in KGE) obtained for a selection of catchment classes (specified in the left column) for two different scenarios (Bench. without reservoirs and Res. including reservoirs) and two different models (HBV-EC and GR4J). A complete overview of the investigated classes can be found in Tables 6 and 7 .

\begin{tabular}{|c|c|c|c|c|c|c|c|}
\hline \multirow[b]{2}{*}{ Class } & \multicolumn{4}{|c|}{$\mathrm{HBV}-\mathrm{EC}$} & \multicolumn{3}{|c|}{ GR4J } \\
\hline & \#catchm. & Bench. & Res. & Diff. & Bench. & Res. & Diff. \\
\hline Aridity $<0.5$ & 33 & 0.453 & 0.593 & 0.140 & & 0.715 & -0.020 \\
\hline Aridity $0.5-1.0$ & 26 & & 0.396 & & & & -0.002 \\
\hline Aridity $>1$ & 10 & & 0.340 & 0.2 & & 0 . & -0.040 \\
\hline Res. cap. $<100 \mathrm{~h}$ & 178 & 0.270 & 0.308 & 0.039 & 0.638 & 0.636 & -0.002 \\
\hline Res. cap. $100-1000 \mathrm{hm}$ & 129 & 0.209 & 0.486 & 0.277 & 0.526 & 0.534 & 0.008 \\
\hline Res ca & 96 & 0.097 & 0. & 0.3 & & 0 . & -0.065 \\
\hline Rel. 1 & 120 & 0.290 & 0.314 & 0.023 & & 0.742 & 0.012 \\
\hline Rel. $r$ & 136 & 0.264 & 0.484 & 0.2 & & 0.659 & -0.001 \\
\hline Rel. res. cap. $>20 \%$ & 147 & 0.071 & 0.397 & 0.326 & 0.353 & 0.305 & -0.048 \\
\hline
\end{tabular}

\subsection{GR4J: model performance does not improve with including reservoirs}

The advantage of working with a modular modeling framework, RAVEN (Craig et al. 2020) in this study, is that it is relatively easy to conduct the same experiment with another model. For this study, we employed the RAVEN implemented GR4J model to investigate if this leads to the same results as for HBV-EC. In this section, the results of this model are shown and compared to the results of the HBV-EC model.

250 The achieved model performance for both scenarios using GR4J are shown in Figure 6. On average, the 251 benchmark scenario (mean KGE of 0.57) leads to better model performance than the reservoir scenario 252 (KGE of 0.56, see also Table 7). Although significant $(\mathrm{p}<0.05)$, the difference in the mean KGE $(-0.013)$ 253 is small and the difference is not significant when the calibration and validation period are swapped (not 254 shown).

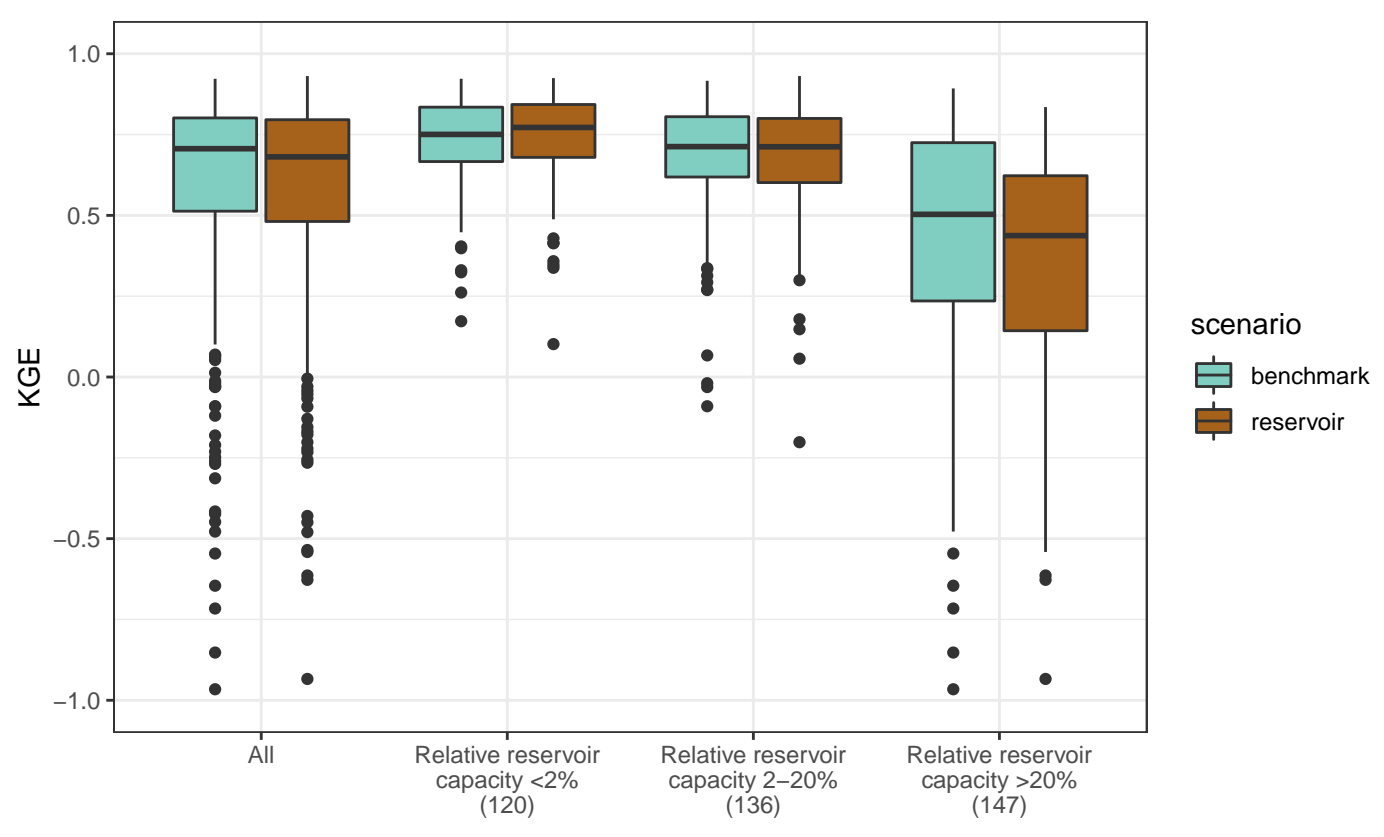

Figure 6. GR4J model performance expressed in KGE for all catchments and three classes with different relative reservoir capacity (number of catchments between brackets). 

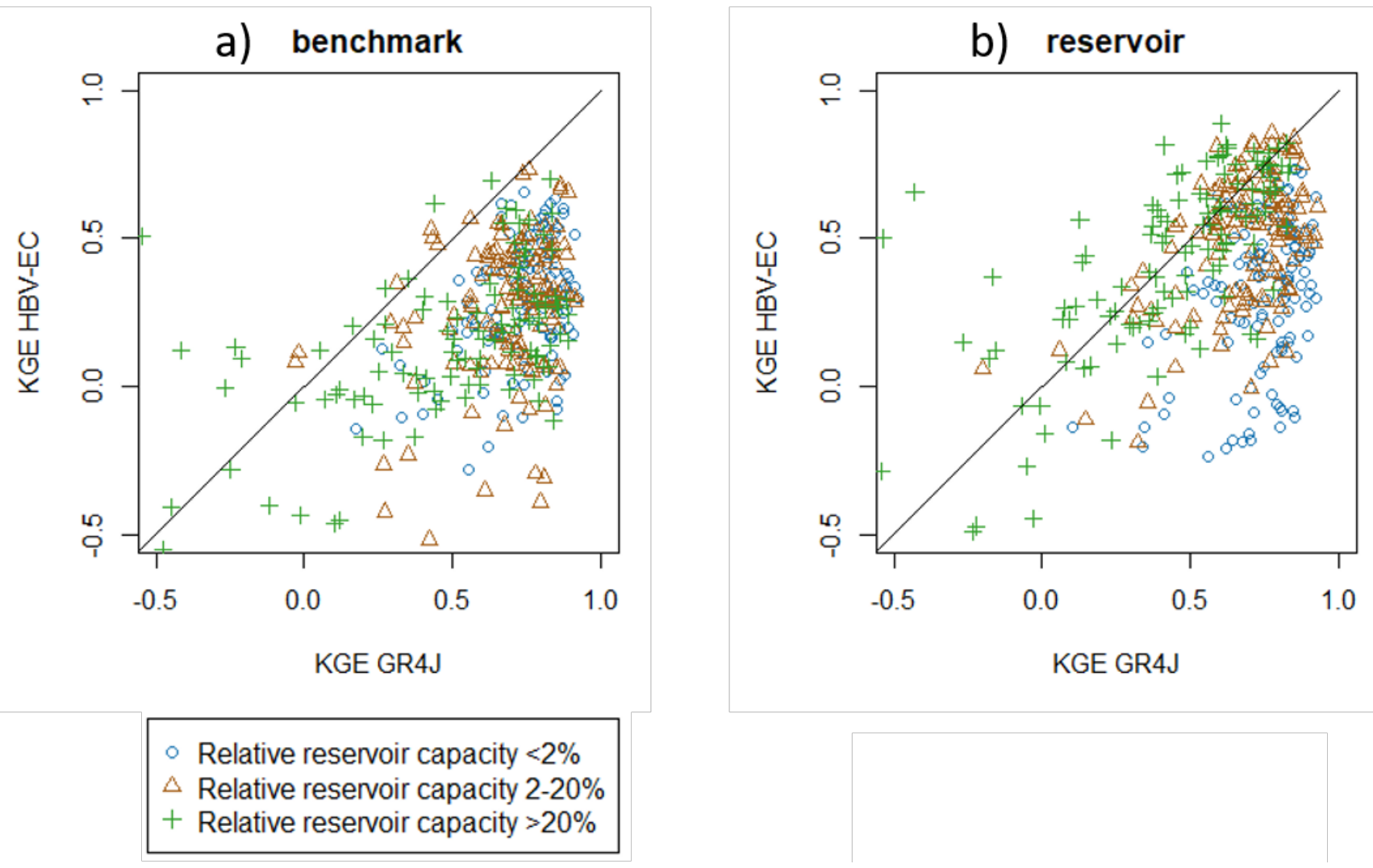

Figure 7. KGE of the HBV-EC model plotted against the KGE of the GR4J model for the benchmark (a) and reservoir scenario $(b)$

Also for the GR4J results, the model performance for both scenarios was linked to several catchment characteristics (Table 7). Again, the total reservoir capacity and relative reservoir capacity appear as relevant characteristics to explain the differences in both scenarios, see Table 2 and Figure 6 , The difference in mean KGE between both scenarios is highest for the classes with the largest relative and absolute reservoir capacity. However, in contrast to the results achieved with HBV-EC, the reservoir scenario in this case leads to lower model performance.

The reservoir scenario does not result in improved model performance, and for some specific characteristics even results in a (slightly) lower performance. The overall model performance for both scenarios is lower and decreases most when including reservoirs in the catchments with a (relatively) larger total reservoir capacity. This can indicate that the way in which the reservoirs were included in this study is not appropriate given the GR4J model structure. But, as was also seen for HBV-EC, the model performance for GR4J is low in highly arid regions and this might also explain some of these results, since arid regions are known to have a high density of smaller reservoirs, leading to cascading effects not accounted for in this study.

Whereas GR4J was able to achieve a higher overall accuracy than HBV-EC, increasing the realism by including the reservoirs did not lead to an improvement in accuracy. Therefore, it remains unclear if we were able to improve fidelity in the model.

\subsection{Structural differences between HBV-EC and GR4J}

The differences between the performance of the two models can be observed by comparing Figures 3 and 6. As an overview of the main differences between the results, Figure 7 shows the KGEs for both 
models with different colors for the relative reservoir capacity classes. Overall, GR4J performs significantly $(\mathrm{p}<0.05)$ better than HBV-EC, both with and without reservoirs included. The differences are smaller for the reservoir scenario. For some catchment characteristic classes, the HBV-EC reservoir scenario performance is better than the GR4J performance, but this is never significant.

The most interesting results are found for the relative reservoir capacity classes. For the scenario with reservoirs included, the difference between the performance of the two models is largest for the class with the smallest relative reservoir capacity, with GR4J performing better. However, the class with the relative largest reservoir capacity shows one of the largest differences between the two models, in favor of HBV-EC. The mean KGE of this class is slightly (but not significantly) higher for the HBV-EC than for GR4J. This is visible in Figure 7b, where the points for the catchments with a relative reservoir capacity $>20 \%$ lay around the 1:1 line. Although no clear conclusions can be drawn from this, it suggests that with a larger relative total reservoir capacity, the reservoir scenario of HBV-EC might work better than GR4J. Possible reasons for these results are discussed below. Model structure, parameters and results of other studies, in which these models were employed are considered.

The models have a different structure and a different number of parameters. HBV-EC has a more complex model structure, including more processes. One of these processes is related to snow, but this is assumed to be negligible because of the low amounts of snowfall in the catchments. Next to that, canopy is explicitly included in the HBV-EC model, which can lead to different evaporation patterns. Specific for GR4J is the groundwater exchange term, which can be a source or sink of water. The flexibility of this model to drain water to the groundwater or to obtain water from seepage helps to close the water balance. Especially when the forcing and streamflow observations do not have a closed balance, this term can resolve input data and calibration data issues. This might explain why GR4J was able to achieve higher model performance than HBV-EC. A thorough evaluation of the quality of the data in the CAMELS-BR basin can confirm this. The more complex HBV-EC model also has more parameters, 16 compared to 6 for GR4J. It might be expected that a more complex model has a better performance, but this also depends on the availability of data. With lower data availability, less complex models are likely to perform better (Grayson and Blöschl, 2001). Nevertheless, the increase in information by including the reservoir may be handled better by this more complex model.

In other studies that compare these two models, but are not focused on reservoirs, varying results are found. Demirel et al. (2015) and Faiz et al. (2018) found that the performance of HBV is higher, but Piotrowski et al. (2017) found that it depends on the catchment. However, in all of these studies, one or only a limited number of catchments were studied. Therefore, they may have had more data available or were better able to estimate values with expert judgement, which might have favored HBV. In their large scale study, Ayzel et al. (2020) found that GR4J had a better performance. Therefore, the difference in performance between the two models as found in this study can be attributed to data availability (favoring a more simple model), differences in model complexity (favoring the inclusion of a reservoir in a more complex model) and data quality issues (that might be resolved when the model has a source/sink term).

\subsection{Synthesis}

Including reservoirs in hydrological models improves the realism of the model and therefore ideally also the accuracy of the model. As demonstrated in our study, this however not trivial. The model performance can improve when reservoirs are included, but overall model performance still remain poor in most of the study catchments. 
Savenije et al. (2014) and Van Loon et al. (2016) have also identified the need to improve the understanding of complex interactions between people and water. The construction of reservoirs is likely one of the most important human actions in terms of impacts on streamflow, because the storage capacity of reservoirs can be substantial. An advantage is that (large) reservoirs are easily visible, which enhances the opportunities to obtain reservoir data with, for example, satellite altimetry (Duan and Bastiaanssen, 2013) or other radar-based remote sensing products (Eilander et al., 2014), especially compared to other human activities such as groundwater abstraction. A global database with larger reservoirs is available (Lehner et al., 2011). Nevertheless, hydrological modeling of reservoirs could still benefit from more information, e.g., about operation rule curves (Turner et al. 2020). In this study, it was found that with limited data, only the total reservoir capacity, it is difficult to obtain good performance when modeling reservoirs.

Several studies have investigated the inclusion of reservoirs in hydrological models at various spatial scales. The scale used in this study is unique, because it is at the same time a small scale (catchment scale) and a large scale (because of the number of catchments). Other studies about reservoirs usually either focus on the global scale (Van Beek et al., 2011; Wanders and Wada, 2015), which requires a further simplification of processes and the exclusion of smaller reservoirs, or focus only on one or a few catchments (van Emmerik et al., 2015; Rougé et al., 2019; Turner et al., 2020), which limits the general applicability. A study comparable to this one is Passaia et al. (2020), which evaluated the model performance across Brazilian rivers when 109 hydropower dams were included in the model. They achieved $21 \%$ increase in KGE with including reservoirs in the MGB model, demonstrating that results are, as confirmed by this study, model dependent and might also depend on how the reservoirs are represented in the model.

Our study shows that simulating reservoirs in a very simplified way, by only including maximum storage capacity in a lake-based approach, does not result in very high model performance, leading to the question how well this can be represented at the global scale. In our modeling approach, the reservoir was always placed at the catchment outlet. Payan et al. (2008) introduced a different method of including reservoirs in a lumped model (GR4J), without accounting for the exact location and achieved good model results. This method, however, requires storage volumes over time as additional input data. Spatially distributed models can better account for the location of a reservoir and can account for reservoir cascades, but come again with higher data demands. We hypothesize that the goal of the reservoir (hydropower versus sustaining agricultural or human consumption needs) influences the reservoir dynamics and may be an important indication if a lake-based approach is useful or not. Besides, a large number of small and informal reservoirs might influence the hydrological system and hamper achieving good performances with hydrological models (Malveira et al., 2012; Mamede et al., 2012, 2018). Overcoming these challenges requires more in-depth knowledge and understanding of the reservoirs and region of study.

\section{CONCLUSION}

The aim of this study was to investigate the effect of including reservoirs in hydrological models (increasing their realism) on their performance (model accuracy) across catchments in Brazil. This was done by including reservoirs in two lumped models (HBV-EC and GR4J) in a simplified way. Lake-type reservoirs were implemented using the modular modeling framework RAVEN, based on the maximum reservoir storage capacity that is provided in the CAMELS-BR database. Model performance was quantified using the Kling Gupta Efficiency (KGE). These are the main findings of this study:

We show that it is possible to improve model performance by including reservoirs in the model structure. This is seen for the HBV-EC model which showed a significant improvement in model performance when reservoirs were included. Adding the reservoir caused an increasing mean KGE from 0.21 to 0.40. The 
largest improvement of model performance occurred in the catchments with the relatively largest reservoir capacity. In these catchments, the benchmark performance was poor in both models (mean KGE of 0.07 for HBV-EC and 0.35 for GR4J), so improvement was also needed the most there. This shows the importance of including reservoirs in hydrological models and the promising improvement of model performance of HBV-EC, where the mean KGE increased to 0.40 for these catchments (For GR4J, the KGE decreased to $0.31)$.

The improvement of model performance also depends on the model structure. While improved model performance was found using the HBV-EC model, the opposite was concluded for GR4J. Overall performance was higher using GR4J, with a mean benchmark KGE of 0.57 , but the performance decreased slightly to a mean KGE of 0.56 when reservoirs were added.

This study shows that a lake-like reservoir implementation can lead to improved model performance, but this also depends on the model structure and on the relative storage capacity of the studied catchment. More knowledge on the local situation, for instance related to the goal of the reservoir, and accounting for cascading reservoir effects (not accounted for in this study) may further improve the simulations.

\section{CONFLICT OF INTEREST STATEMENT}

The authors declare that the research was conducted in the absence of any commercial or financial relationships that could be construed as a potential conflict of interest.

\section{AUTHOR CONTRIBUTIONS}

The research question was formulated by SvL in consultation with CW, TvE, and LM. The simulations and analyses were performend by SvL. SvL wrote the first draft of the manuscript. CW, TvE, GRN, and LM helped with the interpretation and presentation of the results. All authors provided editorial feedback.

\section{REFERENCES}

Almeida, R. M., Hamilton, S. K., Rosi, E. J., Barros, N., Doria, C. R., Flecker, A. S., et al. (2020). Hydropeaking operations of two run-of-river mega-dams alter downstream hydrology of the largest amazon tributary. Frontiers in Environmental Science 8, 1-11. doi:https://doi.org/10.3389/fenvs.2020. 00120

Ayzel, G., Kurochkina, L., and Zhuravlev, S. (2020). The influence of regional hydrometric data incorporation on the accuracy of gridded reconstruction of monthly runoff. Hydrological Sciences Journal , 1-12doi:https://doi.org/10.1080/02626667.2020.1762886

Beck, H., van Dijk, A., Roo, A., Miralles, D., McVicar, T., Schellekens, J., et al. (2016). Global-scale regionalization of hydrologic model parameters. Water Resources Research 52. doi:https://doi.org/10. 1002/2015WR018247

Bergström, S. (1995). The hbv model. In Computer models of watershed hydrology (Highlands Ranch, Colorado: Water Resources Publications). 443-476

Best, J. (2019). Anthropogenic stresses on the world's big rivers. Nat. Geosci. 12, 7-21. doi:https: //doi.org/10.1038/s41561-018-0262-x

Braga, B. P. F., Filho, J. G. C. G., von Borstel Sugai, M. R., da Costa, S. V., and Rodrigues, V. (2012). Impacts of sobradinho dam, brazil. In Impacts of Large Dams: A Global Assessment, eds. C. Tortajada, D. Altinbilek, and A. K. Biswas (Berlin, Heidelberg: Springer Berlin Heidelberg). 153-170. doi:https: //doi.org/10.1007/978-3-642-23571-9\_7 
Carlyle-Moses, D. E. and Gash, J. H. C. (2011). Rainfall Interception Loss by Forest Canopies (Dordrecht: Springer Netherlands). 407-423. doi:10.1007/978-94-007-1363-5_20

Cavalcante, G., Vieira, F., Campos, E., Brandini, N., and Medeiros, P. R. (2020). Temporal streamflow reduction and impact on the salt dynamics of the são francisco river estuary and adjacent coastal zone (ne/brazil). Regional Studies in Marine Science 38, 1-11. doi:https://doi.org/10.1016/j.rsma.2020. 101363

Chagas, V. B., Chaffe, P. L., Addor, N., Fan, F. M., Fleischmann, A. S., Paiva, R. C., et al. (2020). Camels-br: hydrometeorological time series and landscape attributes for 897 catchments in brazil. Earth System Science Data 12, 2075-2096. doi:https://doi.org/10.5194/essd-12-2075-2020

Clark, M. P., Kavetski, D., and Fenicia, F. (2011). Pursuing the method of multiple working hypotheses for hydrological modeling. Water Resources Research 47. doi:https://doi.org/10.1029/2010WR009827

[Dataset] Craig, J. R. (2020). Raven

Craig, J. R., Brown, G., Chlumsky, R., Jenkinson, R. W., Jost, G., Lee, K., et al. (2020). Flexible watershed simulation with the raven hydrological modelling framework. Environmental Modelling \& Software 129, 1-16. doi:https://doi.org/10.1016/j.envsoft.2020.104728

Dantas, J. C., da Silva, R. M., and Santos, C. A. G. (2020). Drought impacts, social organization and public policies in north-eastern brazil: a case study of the upper paraíba river basin. Environ Monit Assess 192, 765-785. doi:https://doi.org/10.1007/s10661-020-8219-0

De Graaf, I. E., Gleeson, T., van Beek, L. R., Sutanudjaja, E. H., and Bierkens, M. F. (2019). Environmental flow limits to global groundwater pumping. Nature 574, 90-94. doi:https://doi.org/10. 1038/s41586-019-1594-4

DelSole, T. and Shukla, J. (2010). Model fidelity versus skill in seasonal forecasting. Journal of Climate 23, 4794-4806. doi:https://doi.org/10.1175/2010JCLI3164.1

Demirel, M. C., Booij, M. J., and Hoekstra, A. Y. (2015). The skill of seasonal ensemble low-flow forecasts in the moselle river for three different hydrological models. Hydrology and earth system sciences 19, 275-291. doi:https://doi.org/10.5194/hess-19-275-2015

Duan, Z. and Bastiaanssen, W. (2013). Estimating water volume variations in lakes and reservoirs from four operational satellite altimetry databases and satellite imagery data. Remote Sensing of Environment 134, 403-416. doi:https://doi.org/10.1016/j.rse.2013.03.010

Eilander, D., Annor, F. O., Iannini, L., and Van de Giesen, N. (2014). Remotely sensed monitoring of small reservoir dynamics: A bayesian approach. Remote Sensing 6, 1191-1210

Engeland, K. and Hisdal, H. (2009). A comparison of low flow estimates in ungauged catchments using regional regression and the hbv-model. Water Resources Management 23, 2567-2586. doi:https: //doi.org/10.1007/s11269-008-9397-7

Faiz, M. A., Liu, D., Fu, Q., Li, M., Baig, F., Tahir, A. A., et al. (2018). Performance evaluation of hydrological models using ensemble of general circulation models in the northeastern china. Journal of Hydrology 565, 599-613. doi:https://doi.org/10.1016/j.jhydrol.2018.08.057

Fantin-Cruz, I., Pedrollo, O., Girard, P., Zeilhofer, P., and Hamilton, S. K. (2015). Effects of a diversion hydropower facility on the hydrological regime of the correntes river, a tributary to the pantanal floodplain, brazil. Journal of Hydrology 531, 810-820. doi:https://doi.org/10.1016/j.jhydrol.2015.10.045

Fleischmann, A., Collischonn, W., Paiva, R., and Tucci, C. (2019). Modeling the role of reservoirs versus floodplains on large-scale river hydrodynamics. Nat. Hazards 99, 1075-1104. doi:https: //doi.org/10.1007/s11069-019-03797-9

Fortin, V. and Turcotte, R. (2006). Le modèle hydrologique mohyse. Note de cours pour SCA7420, Département des sciences de la terre et de l'atmosphere, Université du Québeca Montréal 
441 Grayson, R. and Blöschl, G. (2001). Spatial modelling of catchment dynamics. Spatial patterns in catchment hydrology: observations and modelling , 51-81

Gupta, H. V., Kling, H., Yilmaz, K. K., and Martinez, G. F. (2009). Decomposition of the mean squared error and nse performance criteria: Implications for improving hydrological modelling. Journal of hydrology 377, 80-91. doi:https://doi.org/10.1016/j.jhydrol.2009.08.003

[Dataset] Huard, D. (2020). Calibrating the gr4j-cemaneige hydrological model using ostrich on the raven server

Kirchner, J. W. (2006). Getting the right answers for the right reasons: Linking measurements, analyses, and models to advance the science of hydrology. Water Resources Research 42, 1-5. doi:https: //doi.org/10.1029/2005WR004362

Latrubesse, E., Arima, E., Dunne, T., Park, B., E., V.R., F., d'Horta, Wight, C., et al. (2017). Damming the rivers of the amazon basin. Nature 546, 363-369. doi:https://doi.org/10.1038/nature22333

Lehner, B., Liermann, C. R., Revenga, C., Vörösmarty, C., Fekete, B., Crouzet, P., et al. (2011). Highresolution mapping of the world's reservoirs and dams for sustainable river-flow management. Frontiers in Ecology and the Environment 9, 494-502. doi:http://dx.doi.org/10.1890/100125

Lindström, G., Johansson, B., Persson, M., Gardelin, M., and Bergström, S. (1997). Development and test of the distributed hbv-96 hydrological model. Journal of Hydrology 201, 272-288. doi:https: //doi.org/10.1016/S0022-1694(97)00041-3

Mährlein, M. (2016). Streamflow response to forest fire and salvage harvesting in a snow dominated catchment:a model-based change detection approach. Master's thesis, Albert-Ludwigs-Universität Freiburg

Malveira, V., Araújo, J. d., and Güntner, A. (2012). Hydrological impact of a high-density reservoir network in semiarid northeastern brazil. J. Hydrol. Eng. 17, 109-117. doi:https://doi.org/10.1061/ (ASCE)HE.1943-5584.0000404

Mamede, A., G.L., N.A.M., S., C.M., d. A. J., and Herrmann, H. (2012). Overspill avalanching in a dense reservoir network. Proc. Natl. Acad. Sci. 109, 7191-7195. doi:https://doi.org/10.1073/pnas.1200398109

Mamede, G., Guentner, A., Medeiros, P., de Araújo, J., and Bronstert, A. (2018). Modeling the effect of multiple reservoirs on water and sediment dynamics in a semiarid catchment in brazil. J. Hydrol. Eng. 23, 05018020. doi:https://doi.org/10.1061/(ASCE)HE.1943-5584.0001701

Martel, J.-L., Demeester, K., Brissette, F. P., Arsenault, R., and Poulin, A. (2017). Hmet: a simple and efficient hydrology model for teaching hydrological modelling, flow forecasting and climate change impacts. The International journal of engineering education 33, 1307-1316

[Dataset] Matott, L. (2017). Ostrich: an optimization software tool, documentation and user's guide, version 17.12. 19

Mello, C., Vieira, N., Guzman, J., Viola, M., Beskow, S., and Alvarenga, L. (2021). limate change impacts on water resources of the largest hydropower plant reservoir in southeast brazil. Water 13, 1560. doi:https://doi.org/10.3390/w13111560

Mulligan, M., van Soesbergen, A., and Sáenz, L. (2020). Goodd, a global dataset of more than 38,000 georeferenced dams. Scientific Data 7, 1-8. doi:https://doi.org/10.1038/s41597-020-0362-5

Multsch, S., Krol, M., Pahlow, M., Assuncao, A., Barretto, A., de Jong van Lier, Q., et al. (2020). Assessment of potential implications of agricultural irrigation policy on surface water scarcity in brazil. Hydrol. Earth Syst. Sci. 24, 307-324. doi:https://doi.org/10.5194/hess-24-307-2020

Paca, V. d., Espinoza-Dávalos, G., Moreira, D., and Comair, G. (2020). Variability of trends in precipitation across the amazon river basin determined from the CHIRPS precipitation product and from station records. Water 12, 1244. doi:https://doi.org/10.3390/w12051244 
Paredes-Trejo, F., Barbosa, H., and Lakshmi-Kumar, T. (2017). Validating CHIRPS-based satellite precipitation estimates in northeast brazil. J. Arid Environ. 139, 26-40. doi:https://doi.org/10.1016/j. jaridenv.2016.12.009

Passaia, O., Siqueira, V., Breda, J., Fleischmann, A., and Paiva, R. d. (2020). Impact of large reservoirs on simulated discharges of brazilian rivers. RBRH 25, e17. doi:https://doi.org/10.1590/2318-0331. 252020190084

Payan, J.-L., Perrin, C., Andréassian, V., and Michel, C. (2008). How can man-made water reservoirs be accounted for in a lumped rainfall-runoff model? Water Resources Research 44. doi:https://doi.org/10. 1029/2007WR005971

Pechlivanidis, I., Jackson, B., McMillan, H., and Gupta, H. (2014). Use of an entropy-based metric in multiobjective calibration to improve model performance. Water Resources Research 50, 8066-8083. doi:https://doi.org/10.1002/2013WR014537

Perrin, C., Michel, C., and Andréassian, V. (2001). Does a large number of parameters enhance model performance? comparative assessment of common catchment model structures on 429 catchments. Journal of hydrology 242, 275-301. doi:https://doi.org/10.1016/S0022-1694(00)00393-0

Perrin, C., Michel, C., and Andréassian, V. (2003). Improvement of a parsimonious model for streamflow simulation. Journal of hydrology 279, 275-289. doi:https://doi.org/10.1016/S0022-1694(03)00225-7

Piotrowski, A. P., Napiorkowski, M. J., Napiorkowski, J. J., Osuch, M., and Kundzewicz, Z. W. (2017). Are modern metaheuristics successful in calibrating simple conceptual rainfall-runoff models? Hydrological Sciences Journal 62, 606-625. doi:https://doi.org/10.1080/02626667.2016.1234712

Quick, M. (1995). The ubc watershed model. In Computer models of watershed hydrology (Highlands Ranch, Colorado: Water Resources Publications), chap. 8. 233-280

Rougé, C., Reed, P. M., Grogan, D. S., Zuidema, S., Prusevich, A., Glidden, S., et al. (2019). Coordination and control: Limits in standard representations of multi-reservoir operations in hydrological modeling. Hydrology and Earth System Sciences Discussions , 1-37doi:https://doi.org/10.5194/hess-2019-589

Savenije, H. H., Hoekstra, A. Y., and van der Zaag, P. (2014). Evolving water science in the anthropocene. Hydrology and Earth System Sciences 18, 319-332. doi:https://doi.org/10.5194/hess-18-319-2014

Sivapalan, M., Savenije, H. H., Blöschl, G., et al. (2012). Socio-hydrology: A new science of people and water. Hydrol. Process 26, 1270-1276. doi:https://doi.org/10.1002/hyp.8426

Souza Filho, E. (2009). Evaluation of the upper paraná river discharge controlled by reservoirs. Brazilian Journal of Biology 69, 707-716. doi:https://doi.org/10.1590/S1519-69842009000300024

Tolson, B. A. and Shoemaker, C. A. (2007). Dynamically dimensioned search algorithm for computationally efficient watershed model calibration. Water Resources Research 43. doi:https://doi.org/10.1029/ 2005WR004723

Turner, S. W., Doering, K., and Voisin, N. (2020). Data-driven reservoir simulation in a large-scale hydrological and water resource model. Water Resources Research 56, e2020WR027902. doi:https: //doi.org/10.1029/2020WR027902

Unduche, F., Tolossa, H., Senbeta, D., and Zhu, E. (2018). Evaluation of four hydrological models for operational flood forecasting in a canadian prairie watershed. Hydrological Sciences Journal 63, 1133-1149. doi:https://doi.org/10.1080/02626667.2018.1474219

Van Beek, L., Wada, Y., and Bierkens, M. F. (2011). Global monthly water stress: 1. water balance and water availability. Water Resources Research 47. doi:https://doi.org/10.1029/2010WR009791

Van Emmerik, T., Li, Z., Sivapalan, M., Pande, S., Kandasamy, J., Savenije, H., et al. (2014). Socio-hydrologic modeling to understand and mediate the competition for water between agriculture development and environmental health: Murrumbidgee river basin, australia. Hydrology and Earth 
System Sciences 18, 4239-4259

van Emmerik, T., Mulder, G., Eilander, D., Piet, M., and Savenije, H. (2015). Predicting the ungauged basin: model validation and realism assessment. Frontiers in Earth Science 3, 62

Van Loon, A. F., Gleeson, T., Clark, J., Van Dijk, A. I., Stahl, K., Hannaford, J., et al. (2016). Drought in the anthropocene. Nature Geoscience 9, 89-91

Van Loon, A. F., Rangecroft, S., Coxon, G., Breña Naranjo, J. A., Van Ogtrop, F., and Van Lanen, H. A. (2019). Using paired catchments to quantify the human influence on hydrological droughts. Hydrol. Earth Syst. Sci 23. doi:https://doi.org/10.5194/hess-23-1725-2019

Wada, Y., Bierkens, M. F., De Roo, A., Dirmeyer, P. A., Famiglietti, J. S., Hanasaki, N., et al. (2017). Human-water interface in hydrological modelling: current status and future directions. Hydrology and Earth System Sciences 21, 4169-4193. doi:https://doi.org/10.5194/hess-21-4169-2017

Wanders, N. and Wada, Y. (2015). Human and climate impacts on the 21 st century hydrological drought. Journal of Hydrology 526, 208-220. doi:https://doi.org/10.1016/j.jhydrol.2014.10.047

Woo, M.-k., Thorne, R., Szeto, K., and Yang, D. (2008). Streamflow hydrology in the boreal region under the influences of climate and human interference. Philosophical Transactions of the Royal Society B: Biological Sciences 363, 2249-2258. doi:https://doi.org/10.1098/rstb.2007.2197

Yapo, P. O., Gupta, H. V., and Sorooshian, S. (1996). Automatic calibration of conceptual rainfall-runoff models: sensitivity to calibration data. Journal of Hydrology 181, 23-48. doi:https://doi.org/10.1016/ 0022-1694(95)02918-4

Zhou, T., Nijssen, B., Gao, H., and Lettenmaier, D. P. (2016). The contribution of reservoirs to global land surface water storage variations. Journal of Hydrometeorology 17, 309-325. doi:https://doi.org/10.1175/ JHM-D-15-0002.1

\section{FIGURE CAPTIONS}


van Langen et al. Accuracy vs Realism: Does including reservoirs improve hydrological models?

\section{APPENDIX}




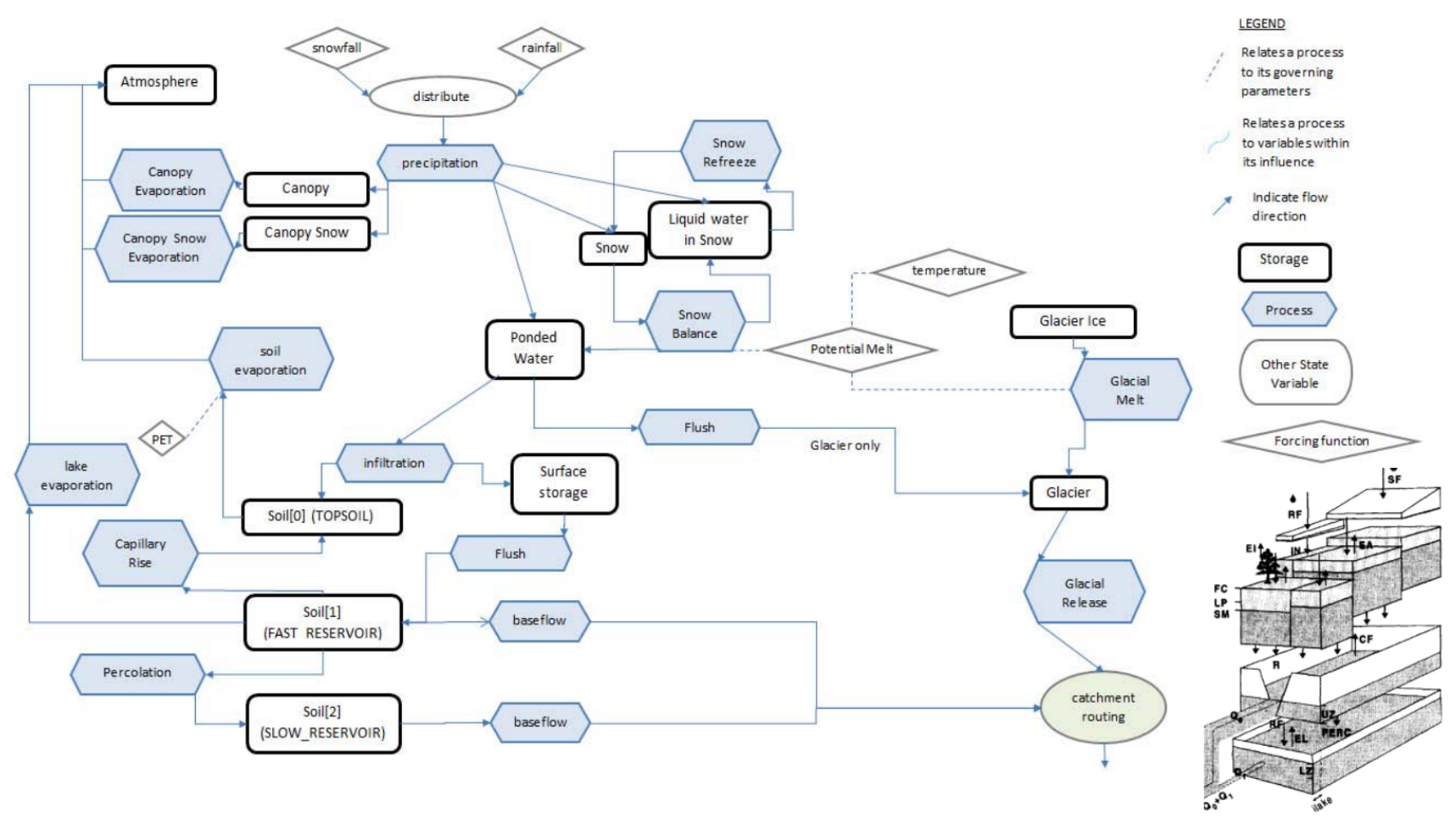

Figure 8. Structure of the HBV-EC model in RAVEN ((Bergström, 1995, Craig, 2020)). This is one of the models used in this study and is shortly described in Section ?? 


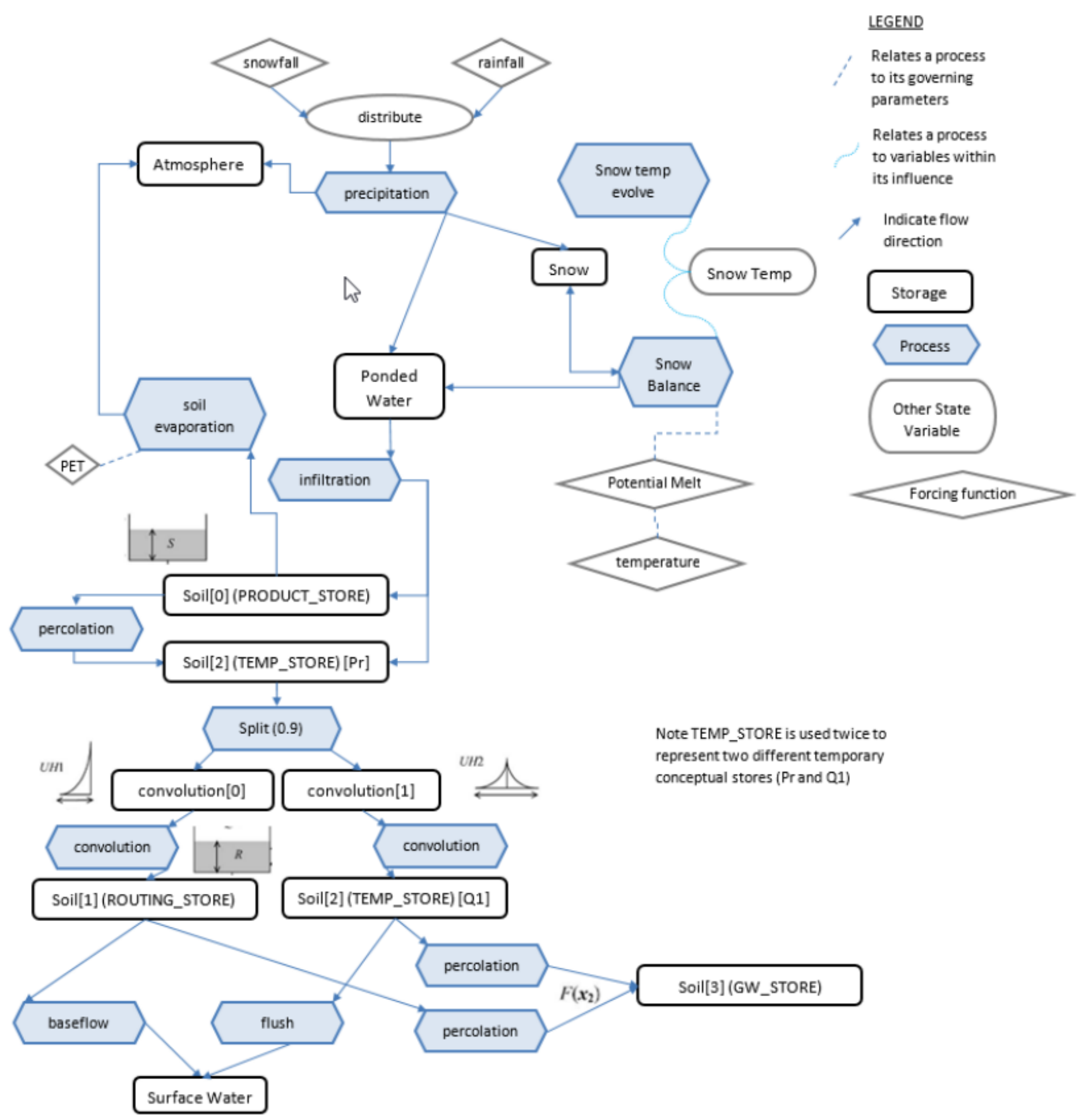

Figure 9. Structure of the GR4J model in RAVEN((Craig, 2020; Perrin et al., 2003) $)$. This is one of the models used in this study and is shortly described in Section ?? 
Table 3. Parameters and ranges used for calibration of the HBV-EC model. Adapted from Mährlein (2016) with value ranges from, Beck et al. (2016), Carlyle-Moses and Gash (2011) and Craig et al. (2020). These are referred to in Sections ?? and 2.2.2

\begin{tabular}{|l|l|l|}
\hline are referred to in Sections ?? and 2.2 .2 & Range \\
\hline Parameter & Description & $0.7-1$ \\
\hline TFr(ain) & Fraction of rainfall not lost by interception & $0.7-1$ \\
\hline TFs(now) & Fraction of snowfall not lost by interception & $0-7$ \\
\hline Tlapse & Temperature lapse rate & $-1-1$ \\
\hline TT & Threshold temperature limit for snow/rain $\left[{ }^{\circ} \mathrm{C}\right]$ & $0-4$ \\
\hline TTi & Temperature interval for mixture of snow and rain $\left[{ }^{\circ} \mathrm{C}\right]$ & $0.5-2.5$ \\
\hline Cmin & Minimum melt factor $\left[\mathrm{mm} /{ }^{\circ} \mathrm{C} / \mathrm{d}\right]$ & $3-4$ \\
\hline Cmax & Maximum melt factor $\left[\mathrm{mm} /{ }^{\circ} \mathrm{C} / \mathrm{d}\right]$ & $0-1$ \\
\hline MRF & Ratio between the melt factor in forest to open areas & $0-4$ \\
\hline CRFR & Melt factor for freezing of liquid water in snow & $0.04-0.07$ \\
\hline WHC & Macimum liquid water content of smow & $0-1$ \\
\hline AM & Aspect melt factor & $0-1$ \\
\hline FC & Field capacity [mm] & $1-6$ \\
\hline BETA & Exponent in soil drainage function & $0.01-0.8$ \\
\hline K1 & Outflow coefficient fast reservoir & $1-10$ \\
\hline ALPHA & Exponent in outflow for fast reservoir & $0.001-0.15$ \\
\hline K2 & Outflow coefficient for slow reservoir &
\end{tabular}

Table 4. Parameters and ranges used for calibration of the GR4J model, ranges from Huard (2020). These are referred to in Sections ?? and 2.2.2

\begin{tabular}{|l|l|l|}
\hline $\mathbf{P} \mathbf{1}$ & Maximum soil moisture content (production store) $[\mathrm{m}]$ & Range \\
\hline $\mathbf{2}$ & Water exchange coefficient with groundwater $[\mathrm{mm} / \mathrm{d}]$ & $-15-10$ \\
\hline $\mathbf{x 3}$ & Reference capacity of the routing store $[\mathrm{mm}]$ & $10-700$ \\
\hline $\mathbf{x} \mathbf{4}$ & lag between rainfall and runoff $[\mathrm{d}]$ & $0-7$ \\
\hline $\mathbf{x 5}$ & Melt factor $\left[\mathrm{mm} / \mathrm{d} /{ }^{\circ} \mathrm{C}\right]$ & $1-30$ \\
\hline $\mathbf{x 6}$ & Air snow coefficient & $0-1$ \\
\hline
\end{tabular}


Table 5. Classes with a short description and the number of catchments in the class. Model performance was assessed for all of these different classes to assess the influence of different catchment characteristics on change of model performance between the benchmark and reservoir scenarios. A more detailed description can be found in the document that comes with the attributes of the CAMELS-BR data set (Chagas et al. 2020)

\begin{tabular}{|c|c|c|}
\hline class & Description & Number of catchments \\
\hline all & All 403 catchments & 403 \\
\hline rand & Random sample & 3 \\
\hline $\operatorname{ar1}$ & Aridity $<0.5$ & 33 \\
\hline $\operatorname{ar2}$ & Aridity $0.5-1.0$ & 262 \\
\hline ar3 & Aridity $>1.0$ & 108 \\
\hline sea1 & Seasonality $<0$ & 74 \\
\hline sea2 & Seasonality 0-0.8 & 157 \\
\hline sea3 & Seasonality $>0.8$ & 172 \\
\hline asy1 & Asynchronicity $<0.05$ & 128 \\
\hline asy2 & Asynchronicity 0.05-0.15 & 151 \\
\hline asy3 & Asynchronicity $>0.15$ & 124 \\
\hline lu1 & Land use $=$ Forest & 151 \\
\hline lu2 & Land use $=$ Crops + Crop Mosaic & 219 \\
\hline lu3 & Land use $=$ Shrub & 33 \\
\hline ca1 & Catchment area $<1000 \mathrm{~km}^{2}$ & 32 \\
\hline ca2 & Catchment area $1000-10000 \mathrm{~km}^{2}$ & 172 \\
\hline ca3 & Catchment area $>10000 \mathrm{~km}^{2}$ & 199 \\
\hline tc1 & Reservoir capacity $<100 \mathrm{hm}^{3}$ & 178 \\
\hline tc2 & Reservoir capacity $100-1000 \mathrm{hm}^{3}$ & 129 \\
\hline tc3 & Reservoir capacity $>1000 \mathrm{hm}^{3}$ & 96 \\
\hline cap1 & Relative reservoir capacity $<2 \%$ & 120 \\
\hline cap2 & Relative reservoir capacity $2-20 \%$ & 136 \\
\hline cap3 & Relative reservoir capacity $>20 \%$ & 147 \\
\hline lat1 & latitude $<-20$ & 182 \\
\hline lat2 & latitude $-20--10$ & 121 \\
\hline lat3 & latitude > -10 & 100 \\
\hline Ion1 & longitude $<-50$ & 131 \\
\hline Ion2 & longitude $-50--45$ & 86 \\
\hline lon3 & longitude $>-45$ & 186 \\
\hline
\end{tabular}


Table 6. Mean KGE of all catchments and different classes for the two scenarios and the difference between them using the HBV-EC model. Significance: *: $p=0.01-0.05, * *: p=0.001-0.01, * * *: p ; 0.001$. Green cells show the largest improvement of model performance and red cells the smallest improvement. These results are explained and discussed in Section 3.1

\begin{tabular}{|l|r|r|r|l|}
\hline Class & Benchmark & Reservoir & Difference & Significance \\
\hline all & 0.209 & 0.401 & 0.192 & $* * *$ \\
\hline rand & 0.421 & 0.475 & 0.054 & - \\
\hline ar1 & 0.453 & 0.593 & 0.140 & $* * *$ \\
\hline ar2 & 0.209 & 0.396 & 0.187 & $* * *$ \\
\hline ar3 & 0.110 & 0.340 & 0.230 & $* * *$ \\
\hline sea1 & 0.275 & 0.393 & 0.118 & $* * *$ \\
\hline sea2 & 0.271 & 0.419 & 0.148 & $* * *$ \\
\hline sea3 & 0.128 & 0.389 & 0.261 & $* * *$ \\
\hline asy1 & 0.194 & 0.407 & 0.213 & $* * *$ \\
\hline asy2 & 0.227 & 0.450 & 0.224 & $* * *$ \\
\hline asy3 & 0.204 & 0.331 & 0.127 & $* * *$ \\
\hline lu1 & 0.193 & 0.398 & 0.205 & $* * *$ \\
\hline lu2 & 0.224 & 0.408 & 0.184 & $* * *$ \\
\hline lu3 & 0.194 & 0.370 & 0.176 & $* * *$ \\
\hline ca1 & 0.175 & 0.370 & 0.195 & $* * *$ \\
\hline ca2 & 0.230 & 0.343 & 0.113 & $* * *$ \\
\hline ca3 & 0.197 & 0.456 & 0.259 & $* * *$ \\
\hline tc1 & 0.270 & 0.308 & 0.039 & $*$ \\
\hline tc2 & 0.209 & 0.486 & 0.277 & $* * *$ \\
\hline tc3 & 0.097 & 0.466 & 0.370 & $* * *$ \\
\hline cap1 & 0.290 & 0.314 & 0.023 & - \\
\hline cap2 & 0.264 & 0.484 & 0.219 & $* * *$ \\
\hline cap3 & 0.071 & 0.397 & 0.326 & $* * *$ \\
\hline lat1 & 0.220 & 0.416 & 0.196 & $* * *$ \\
\hline lat2 & 0.160 & 0.392 & 0.233 & $* * *$ \\
\hline lat3 & 0.247 & 0.381 & 0.134 & $* * *$ \\
\hline lon1 & 0.295 & 0.440 & 0.146 & $* * *$ \\
\hline lon2 & 0.141 & 0.349 & 0.208 & $* * *$ \\
\hline lon3 & 0.175 & 0.397 & 0.221 & $* * *$ \\
\hline
\end{tabular}


Table 7. Mean KGE of all catchments and different classes for the two scenarios and the difference between them using the GR4J model. Significance: *: $\mathrm{p}=0.01-0.05, * *: \mathrm{p}=0.001-0.01, * * *: \mathrm{p} ; 0.001$. Green cells show the largest improvement of model performance and red cells show the largest decrease. These results are explained and discussed in Section ??

\begin{tabular}{|l|r|r|r|l|}
\hline Class & Benchmark & Reservoir & Difference & Significance \\
\hline all & 0.573 & 0.560 & -0.013 & $*$ \\
\hline rand & 0.464 & 0.488 & 0.024 & - \\
\hline ar1 & 0.735 & 0.715 & -0.020 & - \\
\hline ar2 & 0.682 & 0.680 & -0.002 & - \\
\hline ar3 & 0.234 & 0.195 & -0.040 & $*$ \\
\hline sea1 & 0.468 & 0.444 & -0.025 & - \\
\hline sea2 & 0.631 & 0.620 & -0.011 & - \\
\hline sea3 & 0.564 & 0.553 & -0.011 & - \\
\hline asy1 & 0.654 & 0.664 & 0.010 & - \\
\hline asy2 & 0.560 & 0.535 & -0.025 & $*$ \\
\hline asy3 & 0.502 & 0.477 & -0.025 & $*$ \\
\hline lu1 & 0.618 & 0.617 & -0.001 & - \\
\hline lu2 & 0.573 & 0.555 & -0.019 & $*$ \\
\hline lu3 & 0.324 & 0.281 & -0.042 & - \\
\hline ca1 & 0.519 & 0.524 & 0.005 & - \\
\hline ca2 & 0.533 & 0.539 & 0.007 & - \\
\hline ca3 & 0.617 & 0.584 & -0.034 & $* * *$ \\
\hline tc1 & 0.638 & 0.636 & -0.002 & - \\
\hline tc2 & 0.526 & 0.534 & 0.008 & - \\
\hline tc3 & 0.512 & 0.447 & -0.065 & $* * *$ \\
\hline cap1 & 0.730 & 0.742 & 0.012 & - \\
\hline cap2 & 0.660 & 0.659 & -0.001 & - \\
\hline cap3 & 0.353 & 0.305 & -0.048 & $* * *$ \\
\hline lat1 & 0.645 & 0.646 & 0.001 & - \\
\hline lat2 & 0.513 & 0.489 & -0.024 & - \\
\hline lat3 & 0.510 & 0.483 & -0.027 & $*$ \\
\hline lon1 & 0.737 & 0.733 & -0.004 & - \\
\hline lon2 & 0.590 & 0.590 & 0.001 & - \\
\hline lon3 & 0.445 & 0.418 & -0.027 & $*$ \\
\hline
\end{tabular}

